\title{
Saúde Mental na Escola: O que os Educadores Devem Saber
}

\author{
Estanislau, G. M., \& Bressan, R. A. (Orgs.). 2014. Saúde Mental na Escola: o que os educadores devem saber. \\ São Paulo: Artmed.
}

As doenças mentais são compreendidas como transtornos da trajetória da vida, que evoluem a partir de alterações do neurodesenvolvimento e que manifestam seus primeiros sinais na infância. Tal perspectiva enfatiza o papel da escola, pois longe de tratar apenas da questão do aprendizado, os professores e a família possuem condição privilegiada, pois desde que se tornou obrigatória para todas as crianças e jovens brasileiros, esse ambiente passou a ser um local privilegiado de grande concentração de estimulação longitudinal e de grande impacto sobre todos os aspectos da vida.

Nesse sentido, o livro Saúde Mental na Escola: o que os educadores devem saber é publicado com o objetivo de esclarecer melhor o modo como os educadores e os familiares dos alunos podem atuar para prevenção e promoção da saúde mental no contexto escolar. O primeiro capítulo evidencia a falta de conhecimento sobre saúde mental nas escolas brasileiras, o que resulta tanto nas tendências sobre a supervalorização de doenças, discriminação e de medicalização. Essa falta de conhecimento também impede a articulação de projetos sobre o desenvolvimento de habilidades não apenas intelectuais, mas também emocionais e sociais, que contribuirão para o desenvolvimento integral do aluno e constituirá um fator de proteção para problemas mentais no futuro. Porém, isso exige a aproximação de diferentes setores e áreas do conhecimento, por exemplo, educação, saúde e saúde mental, bem como de políticas públicas, para elaboração de novas práticas que atendam a esse objetivo.

Os capítulos de 2 a 6 abordam a diferença entre transtorno e problema mental, definindo o que seriam quadros de transtornos mentais (TM) já instalados e dificuldades mentais intermediárias e/ou mais amenas em que não se configura um TM. A falta de informação confiável e orientação especializada sobre essa condição patológica levam ao estigma, que é um dos problemas de maior impacto na saúde mental, devido à influência negativa que causa no indivíduo. Ao decorrer dos capítulos os temas família e escola são correlacionados, evidenciando a importância de ambos se relacionarem, pois essa aproximação é de grande relevância na promoção da saúde mental. O sistema educacional é destacado como protagonista no contexto de disseminação de saúde e define o termo "aprendizagem socioemocional", referindo-se a um processo fundamental que auxilia o relacionamento interpessoal e introspectivo do indivíduo, ressaltando cinco processos dessa aprendizagem: autoconhecimento, consciência social, tomadas de decisão responsável, habilidades de relacionamento e autocontrole. Essas habilidades, se bem desenvolvidas e trabalhadas, poderão resultar em fatores de proteção contra um possível TM.

O capítulo 7 trata do neurodesenvolvimento e suas principais etapas. Os autores mostram dados sobre como a maturação cerebral está relacionada com o desenvolvimento de habilidades cognitivas, emocionais e sociais. Esse desenvolvimento concomitante depende da interação entre fatores biológicos, como carga genética e o ambiente, que pode ser um facilitador ou um inibidor para do desabrochar das habilidades humanas. Todos esses processos estão associados a períodos de reorganização do cérebro, que podem consistir em grandes aquisições de desenvolvimento.

Os transtornos psiquiátricos são descritos entre os capítulos 8 e 9 , ressaltando a transtorno de ansiedade generalizada, o transtorno de ansiedade social e a fobia social como as mais relevantes na infância e adolescência. A estimativa é que entre $5 \%$ e $13 \%$ da população apresentem esse problema. Já o transtorno obsessivo compulsivo, que afeta entre $1 \%$ e $3 \%$ da população, tem seu tratamento postergado pela falta de conhecimento de suas características.

Há também os transtornos relacionados ao humor, como depressão e transtorno bipolar, em que a criança pode apresentar dificuldades para controlar as emoções, conforme o capítulo 10 . Os capítulos de 11 a 14 tratam dos critérios diagnósticos do TDAH e seus subtipos. Em casos que apresentem persistência de sinais de irritabilidade, oposição e agressividade, podem sugerir quadros definidos como do transtorno de oposição desafiante e do transtorno comportamental. Para todos esses casos, o diagnóstico deve considerar a manifestação dos sintomas dentro de um contexto, levando em consideração dados coletados em uma anamnese e troca de informações com familiares, educadores e outros profissionais de 
saúde que possam estar acompanhando a criança. Seu tratamento pode ser baseado em modalidades de psicoterapia cognitiva comportamental e medicamentos quando necessário.

No capitulo 15, os autores descrevem a esquizofrenia como um transtorno com forte componente genético, associado a alterações do desenvolvimento do cérebro. A prevalência da esquizofrenia é de 1\% na população. Suas características estão relacionadas a diversas apresentações, como um isolamento social, alterações cognitivas, sintomas psicóticos e problemas funcionais. O diagnóstico é feito clinicamente e buscam excluir outras possibilidades que expliquem os sintomas (problemas neurológicos e drogas, por exemplo). Quanto antes o início do tratamento (ação medicamentosa e início de terapias), melhor o prognóstico.

Os transtornos de Espectro Autista (TEAs) e o uso de drogas na adolescência são tratados no capitulo 16 e 17. A causa do TEA é complexa e tem associação com diversos fatores, dentre eles influências genéticas e ambientais. Não há tratamento específico, pois é preciso avaliar as habilidades e dificuldades de cada criança dentro de seu contexto. Apesar do tratamento farmacológico não ser obrigatório no TEAs, o é importante no controle dos sintomas periféricos, como agitação, impulsividade e agressividade.

O capítulo 17 aborda os transtornos relacionados ao uso de drogas. As drogas, como qualquer substância, é capaz de atravessar as barreiras de proteção do cérebro causando inúmeras alterações no comportamento de um indivíduo e podem reforçar o prazer daquela experiência. Em vista disso, o autor traz alternativas a prevenção, classificada em três estágios (prevenção primária, secundária e terciária), em que o sistema escolar apresenta um papel colaborativo, veiculando estratégias que permitam o desenvolvimento e capacitação dos jovens, já que o impacto na população adolescente é bastante alto.

O excesso na preocupação com a imagem corporal e questões referentes ao peso justificam a preocupação com os adolescentes quanto aos transtornos alimentares (TA). O capítulo 18 aborda o TA e suas subdivisões (anorexia nervosa, bulimia nervosa, transtornos alimentares não especificados e transtorno de compulsão alimentar. Não existe causa única para esse tipo de transtorno, e sim fatores de vulnerabilidade, precipitantes e de reforço ao quadro. O tratamento tem por objetivo o restabelecimento do estado nutricional e interrupção dos sintomas comportamentais, pois é comum que outros quadros psiquiátricos estejam associados a esse transtorno.

Por fim, o capítulo 19 aborda os aspectos jurídicos que estão relacionados aos diferentes transtornos, visando o amparo a indivíduos com deficiências e/ ou limitações e também aqueles que apresentem condições que dificultem sua aprendizagem de forma significativa. O objetivo desse capítulo é ampliar as necessidades educacionais especiais, considerando esses indivíduos com grande potencial para ser explorado na escola, por meio de um processo baseado na interação e na diversidade, propiciando um processo mais rico de construção coletiva de conhecimento. Para que essa etapa seja realizada, é necessário que o sistema educacional se aproxime do setor de serviços especializados, como escolas especiais, centros especializados, serviços de saúde e trabalhos de assistência social, sem que não haja a sobrevalorização de nenhuma das partes. Nesse contexto, são expostos alguns aspectos jurídicos contempladas nesse livro, a fim de que o leitor raciocine de forma crítica e adote posicionamentos mais seguros no que tange a assuntos dessa natureza.

Essa obra é de conteúdo altamente relevante para o cenário nacional, pois os autores abordam temas complexos, ressaltando a extrema importância de se avaliar um quadro clínico de transtorno dentro do ambiente escolar. O livro mostra estratégias de prevenção, resguardando-se, porém, do estigma que faz com que muitos pais ou jovens distanciem-se do tratamento por medo de serem ridicularizados. O papel dos pais e dos professores é fundamental para o diagnóstico precoce e observação do tratamento, com a aplicação de novos hábitos no indivíduo a fim de que os efeitos do transtorno sejam minimizados junto ao tratamento medicamentoso, quando necessário.

Recebido em: 09/12/2015

Reformulado em: 06/04/2015

Aprovado em: 04/05/2016 
Sobre a autora:

Janaína Mandra Garcia é discente em Psicopedagogia e de Iniciação Científica do Programa Stricto Sensu em Psicologia Educacional do Centro Universitário FIEO (UNIFIEO), Osasco-SP.

E-mail: janaina.mandra@gmail.com

Contato com a autora:

Av. Franz Voegeli, 300, Continental

CEP: 06020-190

Osasco-SP, Brasil

Psico-USF, Bragança Paulista, v. 21, n. 2, p. 423-425, mai./ago. 2016 